\title{
USO DO METRÔNOMO NA RESSUSCITAÇÃO CARDIOPULMONAR EM UMA UNIDADE DE TERAPIA INTENSIVA
}

\section{USE OF A METRONOME IN CARDIOPULMONARY RESUSCITATION IN AN INTENSIVE CARE UNIT}

\section{USO DEL METRÓNOMO EN LA RESUCITACIÓN CARDIOPULMONAR EN UNIDAD DE TERAPIA INTENSIVA}

\author{
Flávia Silva Ferreira ${ }^{1}$ \\ Laíne Maria Monteiro Garrido² \\ Raquel Chagas Oliveira ${ }^{2}$ \\ Mariana de Almeida Moraes ${ }^{3}$ \\ Cláudia Geovana da Silva Pires ${ }^{4}$ \\ Fernanda Carneiro Mussi
}

\begin{abstract}
Como citar este artigo: Ferreira FS, Garrido LMM, Oliveira RC, Moraes MA, Pires CGS, Mussi FC. Uso do metrônomo na ressuscitação cardiopulmonar em uma unidade de terapia intensiva. Rev baiana enferm. 2018;32:e27912.

Objetivo: relatar a vivência de três enfermeiras assistenciais na utilização do metrônomo durante manobras de ressuscitação cardiopulmonar em unidade de terapia intensiva. Método: trata-se de um relato de experiência que reflete a troca de informações, no cotidiano de trabalho, de três enfermeiras que atuam na unidade de terapia intensiva de um hospital de grande porte em Salvador, Bahia, Brasil. Resultados: o uso continuado do equipamento na ressuscitação cardiopulmonar tem sido indicado para auxiliar na realização das compressões torácicas. O som emitido pelo dispositivo não indica o término de cada ciclo na reanimação e/ou assegura a adequação da profundidade das compressões. Acrescenta ruídos ao ambiente, dificulta a comunicação da equipe multiprofissional e é mais um aparelho a ser configurado no momento da ressuscitação cardiopulmonar, impactando de forma negativa. Conclusão: o metrônomo, nessa experiência, não assegurou a qualidade na ressuscitação cardiopulmonar.
\end{abstract}

Descritores: Parada Cardíaca. Reanimação Cardiopulmonar. Unidade de Terapia Intensiva. Cuidados Críticos. Enfermagem de Cuidados Críticos. Ruído.

Objective: to report the experience of three nurses with the use of a metronome during cardiopulmonary resuscitation maneuvers in an intensive care unit. Method: this is an experience report which reflects the exchange of information in the work routine of three nurses who work in the intensive care unit of a large hospital in Salvador, Bahia, Brazil. Results: continued use of the device in cardiopulmonary resuscitation is indicated to help in chest compressions. The sound emitted by the device does not indicate the end of each cycle in reanimation and does not ensure an adequate depth of compressions. It makes the environment noisier, hampers communication within the multiprofessional staff

Enfermeira. Especialista em Emergência e Unidade de Terapia Intensiva. Salvador, Bahia, Brasil. flavia_s_f@hotmail.com

Enfermeira. Especialista em Enfermagem do Trabalho. Especialista em Emergência e Unidade de Terapia Intensiva. Salvador, Bahia, Brasil.

Enfermeira. Mestre. Professora Assistente da Escola de Enfermagem da Universidade Federal da Bahia. Salvador, Bahia, Brasil.

Enfermeira. Doutora. Professora Adjunta III da Escola de Enfermagem da Universidade Federal da Bahia. Salvador, Bahia, Brasil.

Enfermeira. Doutora. Professora Titular da Universidade Federal da Bahia. Salvador, Bahia, Brasil. 
and is an additional device to be set up at the moment of cardiopulmonary resuscitation, all of which are negative effects. Conclusion: in this experiment, the metronome did not ensure quality in cardiopulmonary resuscitation.

Descriptors: Heart Arrest. Cardiopulmonary Resuscitation. Intensive Care Units. Critical Care. Critical Care Nursing. Noise.

Objetivo: relatar la vivencia de tres enfermeras asistenciales en la utilización del metrónomo durante maniobras de resucitación cardiopulmonar en unidad de terapia intensiva. Método: relato de experiencia que refleja el intercambio de informaciones, en el cotidiano de trabajo, de tres enfermeras que actúan en unidad de terapia intensiva de hospital de gran porte en Salvador, Babía, Brasil. Resultados: el uso continuado del equipo en la resucitación cardiopulmonar ha sido indicado para auxiliar en la realización de las compresiones torácicas. El sonido emitido por el dispositivo no indica el final de cada ciclo en la reanimación y/o asegura la adecuación de la profundidad de las compresiones. Añade ruidos al ambiente, dificulta la comunicación del equipo multiprofesional y es más un aparato a ser configurado en el momento de la resucitación cardiopulmonar, impactando negativamente. Conclusión: el metrónomo, en esa experiencia, no aseguró calidad en la resucitación cardiopulmonar.

Descriptores: Paro Cardíaco. Reanimación Cardiopulmonar. Unidades de Cuidados Intensivos. Cuidados Críticos. Enfermería de Cuidados Críticos. Ruido.

\section{Introdução}

A Parada Cardiorrespiratória (PCR) é uma síndrome de etiologia multifatorial relacionada à instabilidade hemodinâmica, podendo levar a consequências graves, como dano cerebral e de demais órgãos de forma irreversível, ou até mesmo à morte. É considerada um problema de saúde pública e estima-se que ocorram 200.000 casos por ano no Brasil, mesmo com os avanços que vêm ocorrendo na ressuscitação e nas manobras pós-PCR ${ }^{(1)}$.

As diretrizes mundiais de atendimento a PCR ressaltam a importância da manutenção da circulação por meio de compressões torácicas externas efetivas e de alta qualidade, com no mínimo 100 e no máximo 120 compressões por minuto e com profundidade mínima de cinco e máxima de seis centímetros, propiciando o retorno total do tórax ${ }^{(2)}$. Com o intuito de facilitar o cumprimento dessas recomendações, um recurso de comando sonoro vem sendo utilizado para auxiliar na obtenção adequada de uma frequência de compressões torácicas. Dessa forma, o metrônomo é um aparelho capaz de produzir batidas rítmicas e claras a uma frequência regulada pelo usuário, aperfeiçoando o seu desempenho técnico ${ }^{(3)}$.

Considerado um dispositivo de baixo custo e fácil acesso, o metrônomo está presente até em aplicativos de smartphones e é considerado uma alternativa para serviços que não têm desfibriladores com mecanismos de feedback para guiar a ressuscitação cardiopulmonar (RCP) $)^{(2)}$. Autores defendem que a presença de um estímulo sonoro aumenta a qualidade das compressões, pois facilita a realização da frequência recomendada, podendo o socorrista dar maior atenção à força aplicada ao tórax e ao seu retorno adequado ${ }^{(4)}$.

Os benefícios do metrônomo como instrumento de auxílio na PCR têm sido alvo de investigações. Na análise do uso desse recurso em atendimentos de PCR no pré-hospitalar e intra-hospitalar, foi constatada melhor adequação na frequência das compressões torácicas, porém não houve diferença significativa no tempo de Retorno da Circulação Espontânea (RCE), sobrevida dos pacientes e na alta hospitalar ${ }^{(2)}$. Outro estudo demonstrou que a utilização do metrônomo promoveu uma melhoria efetiva na frequência das compressões, entretanto não impactou na melhora da profundidade ${ }^{(5)}$. Os motivos pelos quais isso acontece ainda são desconhecidos, mas tem sido aventada a hipótese de que vários fatores podem contribuir para compressões com profundidade inadequada, incluindo multitarefa, fadiga e distração do profissional de saúde ${ }^{(6)}$. 
A despeito desses resultados, estudos sobre o uso desse aparelho ainda são incipientes. Na busca realizada nas bases de dados eletrônicas da Biblioteca Virtual em Saúde (BVS), sem delimitação de período, utilizando-se os descritores Parada Cardíaca, Reanimação Cardiopulmonar, Unidade de Terapia Intensiva, Cuidados Críticos, Enfermagem de Cuidados Críticos e Ruído com o booleano "AND", empregando-se as combinações "Parada Cardíaca" AND "Unidade de Terapia Intensiva" AND "Ruído", "Parada Cardíaca" AND "Cuidados críticos" AND "Ruído", "Parada Cardíaca" AND "Enfermagem em cuidados críticos" AND "Ruído", "Reanimação Cardiopulmonar" AND "Unidade de Terapia Intensiva" AND "Ruído", "Reanimação Cardiopulmonar" AND "Cuidados críticos" AND "Ruído", "Reanimação Cardiopulmonar" AND "Enfermagem em cuidados críticos" AND "Ruído", não foram encontrados artigos. Desse modo, procedeu-se a busca com as palavras-chave em português: "Metrônomo" AND "Parada Cardíaca" identificando-se três artigos; "Metrônomo" AND "Reanimação cardiopulmonar" encontrando-se dois artigos; e com "Metrônomo" identificou-se 16 artigos, dos quais um era repetido e apenas três tratavam do tema. Utilizando-se as palavras-chave em inglês "Cardiopumonary resuscitation" AND "Metronome", não foram encontrados artigos; empregando-se a palavra "Metronome", foram encontrados 981 artigos, selecionando-se 14 após a leitura do título/resumo, por referirem-se ao tema da experiência, sem delimitação de período. Utilizando-se os descritores Parada Cardíaca; Reanimação Cardiopulmonar; Unidade de Terapia Intensiva; Cuidados Críticos; Enfermagem de Cuidados Críticos e Ruído com o booleano "AND", empregando-se diversas combinações, não foram encontrados artigos. Desse modo, procedeu-se a busca com as palavras-chave, em português e inglês, Metrônomo AND Parada Cardíaca, Metrônomo AND Reanimação cardiopulmonar e Metrônomo, identificando-se 981 artigos, dos quais apenas 14 referiram-se ao tema da experiência após a leitura do título e do resumo.
Com base no exposto, estudos que retratem a vivência dos profissionais da saúde na utilização do metrônomo são relevantes, pois poderão contribuir para o avanço do conhecimento sobre o benefício dessa tecnologia e a reflexão sobre o seu uso nos cenários de atendimento à vítima de PCR. Desta maneira, o presente estudo teve como objetivo relatar a vivência de três enfermeiras assistenciais na utilização do metrônomo durante manobras de RCP em uma Unidade de Terapia Intensiva (UTI).

\section{Método}

Trata-se de um relato de experiência sobre a utilização do metrônomo durante manobras de RCP, em uma UTI com 17 leitos, de um hospital filantrópico de grande porte, situado na cidade de Salvador, Bahia, Brasil. A utilização do metrônomo foi recomendada nessa unidade desde sua implantação, em todas as manobras de RCP, com início no ano de 2015, após a publicação da $A m e-$ rican Heart Association, Guidelines 2015 CPR \& ECC, que sugere a utilização de orientação auditiva para melhor adesão às recomendações referentes à frequência das compressões torácicas. Todos os membros da equipe de saúde dessa UTI estão capacitados para realizar as manobras de RCP. Esse equipamento foi introduzido com o objetivo de melhorar o atendimento às recomendações em PCR, que preconiza de 100 a 120 compressões por minuto a cada ciclo, com uma profundidade de 5 a $6 \mathrm{~cm}$. Após treinamento da equipe de enfermeiros para o manuseio do aparelho, o uso do dispositivo foi adotado no momento da PCR e consiste em um metrônomo com 30 opções de som e ritmo, que podem variar de 35 a 250 batidas por minuto, ajustados por meio de botões de rolagem. O equipamento é programado antes do uso e fica localizado na parte superior do carro de emergência, próximo do posto de enfermagem, ao lado do desfibrilador e dos materiais para intubação orotraqueal, portanto em local de fácil acesso. Existe um metrônomo para cada 8,5 leitos nessa unidade. A experiência relatada reflete a vivência de três enfermeiras assistenciais que atuam na referida UTI, 
a qual tem sido compartilhada no cotidiano do trabalho e em momentos de capacitação sobre a RCP, oportunidade em que ocorreram as reflexões sobre a utilização do equipamento.

\section{Resultados}

Durante uma PCR, a compreensão do cenário no qual o profissional está inserido, a identificação e disponibilização dos recursos disponíveis e a agilidade na execução das determinações para a RCP são imprescindíveis para assegurar a sua qualidade. A exposição do paciente a maior tempo sem fluxo sanguíneo, assim como à subcompressão, consiste em impedimento para o sucesso da ressuscitação.

O atendimento de uma pessoa em PCR na UTI é marcado pela necessidade de otimização do uso do tempo e de habilidades e competências técnico-científicas ${ }^{(7)}$. Além disso, a capacidade da equipe em controlar o estresse é indispensável para a excelência na RCP em ambiente intra-hospitalar ${ }^{(8)}$.

$\mathrm{Na}$ vivência do atendimento de pessoas em PCR, percebeu-se que, em face das situações de risco iminente de morte, a equipe multiprofissional, mesmo em sincronia, enfrenta um momento de alto nível de estresse. É preciso iniciar com prontidão as manobras de reanimação e, concomitantemente, aproximar o carro de emergência, providenciar o material para a realização de via aérea definitiva, preparar e ministrar drogas, manipular desfibrilador e realizar punção de acesso venoso periférico calibroso, na ausência de acesso venoso central. Além da agilidade na execução desses procedimentos, a comunicação entre os integrantes da equipe de saúde deve ser realizada de forma efetiva, para que as atribuições de cada profissional sejam realizadas de forma correta, rápida e organizada, a fim de garantir o RCE e melhorar o prognóstico do paciente. Nesse contexto, a experiência das autoras com o uso do metrônomo considera o estresse vivenciado por elas e pela equipe de atendimento, além das inúmeras demandas de ação e prontidão para assegurar uma efetiva RCP.
Com o intuito de melhorar a efetividade das compressões torácicas, o metrônomo foi adotado na unidade do estudo como dispositivo de comando sonoro. A cada PCR, o dispositivo deve ser ligado e configurado pelo enfermeiro da unidade que irá utilizá-lo, pois possui diversas configurações de ritmo e som que podem ser alteradas entre um uso e outro. O equipamento não possui uma trava de segurança que assegure a manutenção de uma configuração previamente estabelecida, podendo ser facilmente desprogramado. Para facilitar o acesso, durante a RCP, o equipamento situado na unidade fica disposto sobre o carro de emergência e pode ser manipulado por qualquer pessoa, inclusive pela equipe de higienização, o que pode desconfigurá-lo. Assim sendo, constatada a PCR, o enfermeiro deve dirigir atenção para a programação de mais um aparelho, o que exige tempo e constitui-se em mais uma atribuição. Além disso, é importante ressaltar que todo equipamento deve ser devidamente utilizado para garantir a segurança do paciente ${ }^{(9)}$.

Convém destacar que o ruído emitido ritmicamente e de igual intensidade pelo metrônomo utilizado na UTI indica o momento da repetição de cada compressão, mas não sinaliza o término de cada ciclo na RCP. Por isso, cabe ao profissional contar o número de compressões que realiza e pretende atingir, o que é percebido como um aspecto negativo. Recomenda-se, em caso de adultos sem presença de via aérea definitiva, que o profissional sinalize, ao completar 30 compressões torácicas, para que se realizem duas ventilações, até ser alcançado de 100 a 120 compressões por minuto, com monitorização contínua do ritmo. Completada essa frequência de compressões é necessária nova sinalização para checagem de pulso. Em adultos, com presença de via aérea definitiva, deve-se alcançar uma ventilação a cada seis segundos e de 100 a 120 compressões por minuto, sendo necessário sinalizar o momento da checagem de pulso, seguindo a regra já descrita ${ }^{(2)}$.

Observou-se, na prática profissional com o uso do metrônomo, a preocupação do profissional em relação à manutenção do ritmo 
estabelecido, garantindo a frequência das compressões torácicas, mas não assegurando a observância da adequação da profundidade, o que pode comprometer a efetividade do desfecho, tendo um impacto negativo com o seu uso. Autores afirmam que esse fato pode ser resultado da multitarefa requerida pelo uso simultâneo de percepção e técnica de RCP, ao realizar manobras guiadas pelo metrônomo, tendo como consequência redução da profundidade de compressão média ${ }^{(10)}$.

Compressões torácicas de alta qualidade são a base para uma RCP bem-sucedida e é de suma importância para a garantia da sobrevivência e recuperação do paciente ${ }^{(11)}$. Contudo, a orientação do uso do metrônomo está associada à menor profundidade de compressão torácica dos primeiros cinco ciclos $^{(12)}$. Corroboram a experiência das autoras, resultados de estudo no qual a utilização do metrônomo em RCP promoveu apenas adequação da velocidade das compressões, sem resultar em melhorias na profundidade dessas e no retorno do tórax ${ }^{(5)}$. Outra investigação que avaliou o efeito de um metrônomo regular e um metrônomo de voz assistido por telefone na frequência e profundidade das compressões constatou que ambos foram insuficientes para assegurar a qualidade da $\mathrm{RCP}^{(13)}$. Verificou-se também que não houve melhora nas taxas de sobrevida do paciente e no retorno da circulação espontânea em pesquisa realizada com enfermeiros durante a RCP, com e sem utilização do metrônomo ${ }^{(3)}$.

Durante a utilização do dispositivo de comando sonoro, percebeu-se que o ruído emitido é um agente dispersor, atrapalhando a concentração do profissional e a comunicação entre os membros da equipe, gerando mais estresse. O ruído ambiental causado pelo metrônomo pode interferir na comunicação. Por ser um equipamento que soa através de um alto-falante, colabora para um ambiente barulhento em situações reais $^{(14)}$.

É válido destacar que, na RCP, as ordens verbais emitidas pelos profissionais na liderança da equipe devem ser repetidas verbalmente pelo executor antes a após a ação demandada ${ }^{(1)}$, o que exige plena concentração e atenção aos comandos. Como o aparelho emite sons repetitivos e intermitentes, percebe-se e tem-se ouvido queixas dos profissionais da UTI sobre a intensificação do barulho no cenário de atendimento à PCR, pois gera incômodo sonoro, desconcentração e dificuldade de comunicação. Tal observação foi constatada por outro estudo, ao concluir que a informação adicional, seja ela por comando de voz ou sonoro, causa mais distração, resultando em declínio da qualidade da $\mathrm{RCP}^{(13)}$.

Dessa forma, na experiência das pesquisadoras, o uso do metrônomo como auxiliador na RCP, de forma isolada, não foi considerado um recurso capaz de contribuir efetivamente para o atendimento da PCR. Além disso, tem-se que dispor todos os materiais e equipamentos utilizados na RCP, ligar e programar com atenção mais um equipamento que emite um ruído repetitivo de comando durante o uso, sem oferecer feedback da eficiência das manobras de RCP que estão sendo realizadas, no que se refere à profundidade das compressões. O dispositivo tem sido visto pelos enfermeiros como um fator estressante para a equipe, dificultando, muitas vezes, a comunicação entre seus membros. Devido a isso, é de suma importância que qualquer ferramenta utilizada para o fornecimento de instruções funcione não apenas em situações simuladas e controladas, mas também em um contexto real ${ }^{(15)}$.

Assim sendo, é necessário pensar no uso de um dispositivo de feedback audiovisual, em tempo real, que auxilie tanto na efetividade da frequência quanto das compressões, já que apenas a orientação de áudio nem sempre resulta em melhor qualidade da $\mathrm{RCP}^{(10)}$. Os dispositivos de feedback poderão auxiliar melhor na qualidade das manobras de RCP e podem variar desde aparelhos mais simples, como os metrônomos visuais ou auditivos, até monitores/ desfibriladores que fornecem, em tempo real, os parâmetros de frequência, profundidade e pausa das compressões torácicas ${ }^{(1)}$. 


\section{Conclusão}

A experiência vivenciada pelo grupo de enfermeiras em uma unidade de terapia intensiva mostrou que o uso do metrônomo sonoro não foi considerado um recurso que garantisse manobras de RCP de qualidade, uma vez que não assegurava a profundidade das compressões, reduzia a atenção e a concentração dos profissionais e dificultava a comunicação efetiva devido aos ruídos produzidos. Além disso, esse dispositivo precisa ser programado previamente, consistindo em mais um equipamento a ser ligado e programado em um momento crítico, de estresse e de realização de abordagens rápidas e efetivas. Sugere-se que equipamentos mais modernos e que garantam a compressão efetiva sejam introduzidos na prática dos profissionais intensivistas, já que o uso do metrônomo garante apenas a adesão às recomendações referentes à velocidade das compressões. Acredita-se também que os relatos de vivências em outros serviços servirão para confrontar ou confirmar os achados desta experiência.

\section{Colaborações:}

1. concepção, projeto, análise e interpretação dos dados: Flávia Silva Ferreira, Laíne Maria Monteiro Garrido e Raquel Chagas Oliveira;

2. redação do artigo e revisão crítica relevante do conteúdo intelectual: Flávia Silva Ferreira, Laíne Maria Monteiro Garrido, Raquel Chagas Oliveira, Mariana de Almeida Moraes, Cláudia Geovana da Silva Pires e Fernanda Carneiro Mussi;

3. aprovação final da versão a ser publicada: Mariana de Almeida Moraes, Cláudia Geovana da Silva Pires e Fernanda Carneiro Mussi.

\section{Referências}

1. Gonzalez MM, Timerman S, Gianotto-Oliveira R, Polastri TF, Canesin MF, Schimidt A, et al. I Diretriz de Ressuscitação Cardiopulmonar e Cuidados Cardiovasculares de Emergência da Sociedade Brasileira de Cardiologia. Arq Bras Cardiol [Internet]. 2013 [cited 2018 Jul 20];101(2
Suppl 3):1-221. Available from: http://www. scielo.br/scielo.php?script=sci_arttext\&pid=S0066782X2013003600001\&lng=en

2. American Heart Association. Guidelines for Cardiopulmonary Resuscitation and Emergency Cardiovascular Care. Destaques da atualização das Diretrizes da AHA 2015 para RCPeACE. Texas(EUA); 2015 [cited 2018 Jul 20]. Available from: https:// eccguidelines.heart.org/wp-content/uploads /2015/10/2015-AHA-Guidelines-HighlightsPortuguese.pdf

3. Botelho RMO, Campanharo CRV, Lopes MCBT, Okuno MFP, Góis AFT, Batista REA. Uso do metrônomo durante a ressuscitação cardio-pulmonar na sala de emergência de um hospital universitário. Rev Latino-Am Enfermagem [Internet]. 2016 [cited 2018 Nov 7];24:e2829. Available from: http://www.scielo. $\mathrm{br} /$ scielo.php?script $=$ sci_arttext $\&$ pid $=$ S0104$11692016000100427 \& \operatorname{lng}=e n$

4. Fonseca AHIRM, Fonseca FIRM, Oliveira RG, Barral TN, Gonzalez MM, Timerman S. Avaliação da frequência e profundidade das compressões torácicas realizadas com o uso de metrônomo. Rev Bras Clin Med [Internet]. 2012 [cited 2018 Jul 21];10(3):175-8. Available from: http://files.bvs.br/ upload/S/1679-1010/2012/v10n3/a2895.pdf

5. Zimmerman E, Cohen N, Maniaci V, Pena B, Lozano JM, Linares M. Use of a metronome in cardiopulmonary resuscitation: a simulation study. Pediatrics [Internet]. 2015 [cited 2018 Jul 21];136(5):905-11. Available from: https:// www.ncbi.nlm.nih.gov/pubmed?db=PubMed \&cmd=Retrieve\&list_uids $=26459645$

6. Bae J, Chung TN, Je SM. Effect of the rate of chest compression familiarised in previous training on the depth of chest compression during metronome-guided cardiopulmonary resuscitation: a randomised crossover trial. BMJ Open. 2016 Feb [cited 2018 Jul 21];6(2):e010873. Available from: https://www.ncbi.nlm.nih.gov/pubmed/26873050

7. Inoue KC, Versa GLGS, Murassaki ACY, Melo WA, Matsuda LM. Estresse ocupacional em enfermeiros intensivistas que prestam cuidados diretos ao paciente crítico. Rev bras enferm [Internet]. 2013 [cited 2018 Jul 22];66(5):722-9. Available from: http://www.scielo.br/scielo.php?script=sci_ arttext\&pid=S0034-71672013000500013\&lng=en

8. Citolino CM, Santos ES, Silva RDCG, Nogueira LDS. Fatores que comprometem a qualidade da ressuscitação cardiopulmonar em unidades de 
internação:percepçãodoenfermeiro. RevEscEnferm USP [Internet]. 2015 [cited 2018 Jul 22];49(6):90814. Available from: https://www.ncbi.nlm.nih. gov/pubmed?db=PubMed\&cmd=Retrieve\&list_ uids $=27419673$

9. Mendes RNC, Carmo AFS, Nunes R, Hassad MCL, Rossaneis MA. Percepções de enfermeiros sobre o uso de equipamentos em Unidade de Terapia Intensiva. Rev enferm UFPE on line. 2013 [cited 2018 Jul 22];8(7):1904-11. Available from: https:// periodicos.ufpe.br/revistas/revistaenfermagem/ article/view/9865/10093

10. Oh JH, Lee SJ, Kim SE, Lee KJ, Choe JW, Kim CW. Effects of audio tone guidance on performance of CPR in simulated cardiac arrest with an advanced airway. Resuscitation [Internet]. 2008 Nov [cited 2018 Nov 13];79(2):273-7. Available from: https:// www.ncbi.nlm.nih.gov/pubmed/18691796

11. Vahedian-Azimi A, Hajiesmaeili M, Amirsavadkouhi A, Hamidreza J, Morteza I, Seyed JM, et al. Effect of the Cardio First Angel ${ }^{\mathrm{TM}}$ device on CPR indices: a randomized controlled clinical trial. Crit Care [Internet]. 2016 May [cited 2018 Jul 22];20(1):147. Available from: https://www.ncbi.nlm.nih.gov/ pubmed/27184664?dopt=Abstract

12. Chung TN, Kim SW, You JS, Cho YS, Chung SP, Park I, et al. The specific effect of metronome guidance on the quality of one-person cardiopulmonary resuscitation and rescuer fatigue. J Emerg Med [Internet]. 2012 [cited 2018 Nov 13];43(6):1049-54. Available from: https://www. ncbi.nlm.nih.gov/pubmed/22445676
13. Tulder RV, Roth D, Krammel M, Laggner R, Schriefl C, Kienbacher C, et al. Efectos de un metrónomo (de voz) en la frecuencia y profundidad de compresiones de una reanimación cardiopulmonar por un primer interviniente asistida telefónicamente. Un ensayo de simulación, aleatorizado y ciego. Emergencias [Internet]. 2015 [cited 2018 nov 6];27(6):357-63. Available from: https://dialnet.unirioja.es/servlet/ articulo?codigo $=5379949$

14. Park SO, Hong CK, Shin DH, Lee Jun Ho, Hwang SY. Efficacy of metronome sound guidance via a phone speaker during dispatcher-assisted compression-only cardiopulmonary resuscitation by an untrained layperson: a randomised controlled simulation study using a manikin. Emerg Med J [Internet]. 2013 [cited 2018 Nov 13];30(8):657-61. Available from: https://www.ncbi.nlm.nih.gov/ pubmed/23018287

15. Scott G, Barron T, Gardett I, Broadbent $M$, Downs H, Devey L, et al. Can a Software-Based Metronome Tool Enhance Compression Rate in a Realistic 911 Call Scenario Without Adversely Impacting Compression Depth for DispatcherAssisted CPR? Prehosp Disaster Med [Internet]. 2018 [cited 2018 Nov 13];33(4):399-405. Available from: https://www.ncbi.nlm.nih.gov/pubmed/30033904

Recebido: 31 de agosto de 2018 Aprovado: 29 de novembro de 2018 Publicado: 27 de dezembro de 2018

A Revista Baiana de Enfermagem utiliza a Licença Creative Commons - Atribuição-NãoComercial 4.0 Internacional. https://creativecommons.org/licenses/by-nc/4.0/

Este artigo é de acesso aberto distribuído sob os termos da Licença Creative Commons (CC BY-NC). Esta licença permite que outros remixem, adaptem e criem a partir do seu trabalho para fins não comerciais. Embora os novos trabalhos tenham de lhe atribuir o devido crédito e não possam ser usados para fins comerciais, os usuários não têm de licenciar esses trabalhos derivados sob os mesmos termos. 